\title{
Representações sociais da violência contra a mulher na perspectiva da enfermagem
}

\author{
Sandra Maria Cezar Leal \\ Marta Julia Marques Lopes ${ }^{2}$ \\ Maria Filomena Mendes Gaspar ${ }^{3}$
}

LEAL, S.M.C.; LOPES, M.J.M.; GASPAR, M.F.M. Social representations of violence against women in the nursing perspective. Interface - Comunic., Saude, Educ., v.15, n.37, p.409-24, abr./jun. 2011.

Violence against women is a severe Public Health problem that occurs worldwide within all social classes. This study aimed at learning the social representations of violence against women in the perspective of nurses studying at a Nursing School in Lisbon, Portugal. Supported by the social representations, an exploratory research was carried out with the participation of 150 nurses. The data were collected through a questionnaire with five stimulating questions. For the analysis, the software DataVic 4.3 was utilized. Results evidence that the social representations of violence against women are restricted to the consensus universe which produces them and which is constituted, above all, by informal conversation and daily life. They also indicate that violence is not understood as a health problem. We consider that the theoretical foundation about the theme and the institutional involvement of the Health Services will contribute to the inclusion of violence against women in the Public Health agenda.

Keywords: Nursing. Gender and health. Violence. Violence against women.
A violência contra a mulher constitui grave problema de Saúde Pública; ocorre no mundo inteiro em todas as classes sociais. O objetivo do estudo foi conhecer as representações sociais da violência contra a mulher na perspectiva de enfermeiras alunas de uma Escola Superior de Enfermagem de Lisboa/Portugal. Realizouse pesquisa exploratória com respaldo das representações sociais, da qual participaram cento e cinquenta enfermeiras, sendo os dados coletados por meio de questionário. Para análise, utilizou-se o software DataVic 4.3. Resultados apontam que as representações sociais da violência contra a mulher estão restritas ao universo consensual pelo qual são produzidas, constituído, sobretudo, pela conversação informal e pela vida cotidiana. Apontam, também, que a violência não é entendida como um problema de saúde. Considera-se que o embasamento teórico sobre o tema e o envolvimento institucional dos Serviços de Saúde contribuirão para a inserção da violência contra a mulher na agenda da Saúde Pública.

Palavras-chave: Enfermagem. Gênero e saúde. Violência. Violência contra a mulher.

\footnotetext{
${ }^{1}$ Curso de Enfermagem, Universidade do Vale do

Rio dos Sinos. Avenida Unisinos, 950. Bairro Cristo Rei, São Leopoldo, RS, Brasil. 93.022-000. sandral@unisinos.br 2 Programas de Pósgraduação, Mestrado e Doutorado, Escola de Enfermagem,

Universidade Federal do

Rio Grande do Sul.

${ }^{3}$ Conselho directivo,

Escola Superior de

Enfermagem de Lisboa.
} 


\section{Introdução}

Nesta pesquisa são abordadas as Representações Sociais da violência contra a mulher perpetrada por (ex-)parceiro íntimo, temática que faz parte de um grupo de estudos ${ }^{4}$ e constitui grave problema de Saúde Pública, que atinge mulheres de todas as classes sociais em todo o mundo.

A violência contra a mulher é conceituada como "sofrimento e agressões dirigidos especificamente às mulheres, pelo fato de serem mulheres. [...] especialmente a violência que se dá por agressores conhecidos, próximos e de relacionamento íntimo, com experiências de vida usuais" (Schraiber, D'Oliveira, 1999, p.12). Portanto, além da dor física, a mulher também sente a dor de ser agredida por alguém que ama ou que amou, e o domicílio, que deveria ser o local de proteção, é transformado em espaço de vulnerabilidade a esses eventos.

Muitas das mulheres em situação de violência, que chegam às emergências de saúde, não são identificadas como tal, e o tratamento se restringe ao ferimento ou à lesão física. Sendo assim, se diante do trauma físico, a violência é invisibilizada, questiona-se: de que modo a violência contra mulheres é identificada nos atendimentos de Saúde, quando as queixas não estão diretamente relacionadas à agressão?

Resultados de estudos apontam que, entre as usuárias dos serviços de saúde, é alta a prevalência de mulheres que convivem ou já conviveram com a violência (Marinheiro, Vieira, Souza, 2006; Schraiber et al., 2002). Entretanto, o registro dos casos de violência contra a mulher, na maioria das vezes, não é realizado nem identificado, pois o atendimento está direcionado aos sintomas, às queixas clínicas, e à parte do corpo supostamente comprometida (Leal, 2003). Considera-se importante ressaltar o fato de as mulheres se calarem diante da violência sofrida, seja por vergonha, por culpa ou por se sentirem responsáveis pela agressão.

Mulheres em situação de violência tendem a utilizar, com maior frequência, os serviços de saúde, e a assistência tem baixo poder resolutivo, acarretando maior custo ao Sistema de Saúde, em consequência do seu uso repetitivo e ineficaz. Além disso, as mulheres, devido ao sofrimento provocado pela violência, tendem a negligenciar o cuidado consigo mesmas e com os outros. Essas são mais propensas: à entrada tardia no pré-natal, à baixa adesão ao exame de prevenção do câncer cérvico-uterino, à realização de sexo inseguro, ao abuso de álcool e tabaco, e ao uso de outras drogas (Schraiber et al., 2002). Esses aspectos demonstram que as equipes da Saúde não estão preparadas para identificar as mulheres em situação de violência, o que se agrava quando elas não expressam verbalmente a agressão.

Resultados de pesquisa realizada com profissionais de Saúde de um serviço público de emergência (Leal, Lopes, 2005) evidenciaram reações de defesa acionadas pelas trabalhadoras de enfermagem no enfrentamento ao cuidado do paciente hospitalizado por agressão: a fragmentação da relação técnico-paciente; a despersonalização e negação da importância do indivíduo; o distanciamento e negação de sentimentos. As estratégias para suportar o "sofrimento" são criadas entre o grupo, por acordos, como o auxílio mútuo no cuidado aos pacientes.

Considera-se que são muitos os sistemas de defesa utilizados pelos profissionais para darem conta do dia a dia de trabalho em um serviço de emergência; entretanto, nos serviços básicos de saúde, as estratégias também estão presentes e manifestadas de várias formas, dentre as quais: pela naturalização e invisibilização de usuárias e usuários em situação de violência, pela "rotulação" de algumas mulheres de poliqueixosas, entre outras.
${ }^{4}$ Grupo de Estudos em Saúde Coletiva (GESC) vinculado ao programa de Pós-Graduação Mestrado e Doutorado em Enfermagem da Universidade Federal do Rio Grande do Sul (UFRGS). 
A violência de gênero naturalizada pelo senso comum também faz parte do cotidiano dos profissionais de saúde, o que pode interferir nas condutas dos atendimentos às mulheres em situação de violência. Resultados de estudo que estimou a violência de gênero vivida por trabalhadoras de enfermagem de um hospital geral de São Paulo apontaram que a violência por parceiro íntimo foi a mais frequente, poucas profissionais buscaram ajuda e 31,9\% das entrevistadas não perceberam 0 vivido como violento (Oliveira, D'Oliveira, 2008).

Em pesquisa realizada em Portugal, sobre a representação dos profissionais da saúde em face da questão, identifica-se que esses, com frequência, espelham-se na prática clínica de tratar quase exclusivamente as manifestações orgânicas de uma patologia (Gonçalves, 2004). Portanto, identificar e referenciar mulheres vítimas de violência é ir além do que prestar os cuidados clínicos necessários, é tratar e resolver a causa do adoecimento (Gonçalves, 2004).

Pelo inquérito nacional sobre violência de gênero, realizado em Portugal, em todos os distritos do continente, no ano de 2007, cujos participantes foram mil mulheres e mil homens com 18 anos ou mais de idade, identificou-se que cerca de uma em cada três portuguesas é vítima de violência, que ocorre na esfera da vida privada, e os agressores são, sobretudo, (ex-)companheiros íntimos (Lisboa, 2008). Em 2008, o mesmo inquérito foi realizado na Região Autônoma dos Açores, com 358 homens e 351 mulheres; nessa região do país, a prevalência da violência contra as mulheres foi de 53,3\%, valor mais elevado do que a identificada no continente (38\%), em 2007 (Lisboa, 2009).

Resultados de outro estudo realizado em Portugal, sobre violência contra a mulher e os custos da saúde, apontam que $21 \%$ das mulheres inquiridas, com 18 anos ou mais, que foram vítimas de violência, procuraram atendimento hospitalar em decorrência da agressão (Carmo, 2006). Entretanto, somente $9 \%$ das mulheres que sofreram violência buscaram os Centros de Saúde (CSs). A autora destaca que esses, pelas características de proximidade, poderiam mais facilmente identificar o ato e o agressor; porém, isso ocorre com pouca frequência. Destaca, ainda, que os profissionais dos CSs deveriam ser mais sensibilizados para visibilizarem as mulheres nessas situações, sobretudo, porque a violencia doméstica é considerada crime no país e a denúncia pode ocorrer a partir daí. Outra questão apontada é a importância de haver ligação dos CSs com as casas-abrigo, para onde podem ser encaminhadas as mulheres em situação de violência (Carmo, 2006).

As representações sociais, como formas interpretativas da realidade social, apontam para as bases nas quais estão assentadas as condutas profissionais e, nesse caso, desempenham papel nos processsos de atenção à saúde desencadeados nos atendimentos. Neste contexto, considera-se que identificar as Representações Sociais da violência, na compreensão das enfermeiras, contribui com elementos teóricos para análise, que poderão subsidiar e instrumentalizar a construção de um processo amplo de atenção, comprometido com a integralidade do atendimento à saúde, evitando, assim, a reprodução de certas formas de atendimento, marcadas pelas desigualdades sociais e de gênero ao se "olhar" a violência.

Opta-se por se adotarem bases conceituais das Representações Sociais, definidas, por Moscovici, como "uma modalidade de conhecimento particular que tem por função a elaboração de comportamentos e a comunicação entre indivíduos" (Moscovici, 1978, p.26).

Nas sociedades contemporâneas, existem duas classes distintas de universos de pensamento: os consensuais e os reificados (Moscovici, 2003). Nos reificados é que "se produzem e circulam as ciências e o pensamento erudito em geral, com sua objetividade, seu rigor lógico e metodológico, sua teorização abstrata, sua compartimentalização em especialidades e sua estratificação hierárquica" (Sá, 2004, p.28). Os consensuais se constituem, especialmente, na conversação informal na vida cotidiana, pela qual são produzidas as Representações Sociais (Sá, 2004; Arruda, 2002). A diferença entre um universo e outro não indica isolamento, nem hierarquia entre eles, apenas propósitos diversos.

Analisar as implicações das Representações Sociais das(os) enfermeiras(os) sobre a violência contra as mulheres requer que a violência seja compreendida a partir desses universos construídos nas mentalidades e nos serviços, nos quais estão inseridas as práticas terapêuticas. Acredita-se que é na interação desses dois universos que se constroem as possibilidades concretas de enfrentamento ao adoecimento advindo de atos violentos.

O objetivo deste estudo é apreender as dimensões significantes das Representações Sociais da violência contra a mulher em um grupo de enfermeiras(os) de uma Escola pública de Enfermagem de Lisboa. 
Nessa perspectiva, a questão norteadora pode ser assim sintetizada: Quais as Representações Sociais da violência contra a mulher por parte de enfermeiras(os) estudantes do Curso de Complemento de Formação em Enfermagem e da Licenciatura de Especialização em Enfermagem de Saúde Materna e Obstetrícia, de uma escola pública de Enfermagem de Lisboa?

\section{Metodologia}

Trata-se de um estudo exploratório qualitativo, com respaldo teórico das Representações Sociais (Moscovici, 1978), que se alimentam "não só das teorias científicas, mas também dos grandes eixos culturais, das ideologias formalizadas, das experiências e das comunicações quotidianas" (Vala, 2006, p.458). Portanto, considera-se que esses elementos poderão auxiliar a compreender as representações da violência contra a mulher, na perspectiva de enfermeiras(os) e, assim, poder contribuir para pensar o enfrentamento do problema na Área da Saúde. O estudo foi realizado em uma Escola Superior de Enfermagem de Lisboa, Portugal. Participaram da pesquisa cento e cinquenta enfermeiras (os) (cento e trinta mulheres e vinte homens), estudantes do Curso de Complemento de Formação em Enfermagem e da Licenciatura de Especialização em Enfermagem de Saúde Materna e Obstetrícia, de uma Escola pública de Enfermagem, de Lisboa. A amostra foi constituída por seleção aleatória, seguindo o critério de incluir todos os sujeitos com interesse em participar do estudo e que estavam presentes na sala aula, nos dias marcados para a coleta dos dados, que foi ali realizada, no período de novembro a dezembro de 2008 , por meio de um instrumento individual, com cinco questões-estímulo: "Quando penso em violência, lembro-me de... "; "Quando penso em violência contra a mulher, lembro-me de..."; "Quando penso em cuidar de uma mulher que procurou o serviço de saúde por ter sido agredida pelo (ex-)marido, (ex-)companheiro, (ex-)namorado, lembro-me de..."; "Quando penso na contribuição da minha formação acadêmica e profissional, para identificar uma mulher vítima de violência, lembro-me de..."; "Quando penso se a violência contra a mulher é um problema de Saúde Pública ou um caso de polícia, lembro-me de...". Foi solicitado que o participante respondesse a cada estímulo com, no máximo, cinco palavras ou frases curtas. Seguiramse os critérios éticos para pesquisa, vigentes em Portugal, e solicitou-se que cada participante lesse e assinasse um Termo de Consentimento Livre e Esclarecido, seguindo-se as orientações preconizadas pela Resolução 196/96 (Brasil, 1996): consentimento informado em duas vias, ficando uma com o participante, constando os telefones e endereços eletrônicos dos pesquisadores, disponibilizando o contato; explicitação, aos entrevistados, sobre seu direito de interromper, a qualquer momento, o preenchimento das questões de pesquisa; a garantia do anonimato; garantia de retorno dos resultados, após a conclusão da pesquisa.

Para a análise, reduziram-se todas as palavras associadas a cada um dos estímulos, sem categorizá-las; deixaram-se os adjetivos e substantivos no masculino e singular e os verbos no infinito, baseando-se exclusivamente no critério de raiz etimológica da palavra, pois, para qualquer redução em termos de significados, é necessário buscar o recurso de juízes (Oliveira, Araújo, 1999; Amâncio, Carapinheiro, 1993). Utilizou-se o software DtmVic 4.0 (Lebart, 2008). Os universos semânticos associados à violência contra a mulher foram identificados para cada um dos estímulos, com as palavras ou produções em texto livre (as variáveis qualitativas), pela Análise Fatorial de Correspondências (AFC) Simples.

A AFC Simples é a extração dos fatores ou universos semânticos das palavras, que são as variáveis qualitativas. Elas surgem em polos positivos e negativos, que correspondem a sua projeção nos eixos fatoriais; sem conotação valorativa, é possível fazer atribuições de significados a conjunto de palavras agrupadas em fatores. A contribuição absoluta é o nível de participação de cada palavra (variável) na construção ou definição de um eixo ou fator, que é explicado pelas variáveis que têm valores mais elevados de contribuição absoluta (Oliveira, Amaral, 2007). Portanto, o peso que a palavra tem na explicação do fator é identificado pelo valor numérico das contribuições absolutas (Gaspar et al., 2000). 


\section{Resultados e discussão}

Conforme já citado anteriormente, a pesquisa foi constituída por cento e cinquenta enfermeiras(os), alunas(os) do Curso de Complemento de Formação em Enfermagem (99) e da Licenciatura de Especialização em Enfermagem de Saúde Materna e Obstetrícia (51), de uma Escola pública de Enfermagem, de Lisboa.

O Curso de Complemento de Formação em Enfermagem, criado pela Portaria 799-E/99, destinase à atribuição do grau de licenciado em Enfermagem aos enfermeiros titulares do grau de bacharel ou equivalente legal (Ordem dos Enfermeiros, 2008).

A seguir, apresenta-se a caracterização dos sujeitos quanto ao sexo, faixa etária, curso e tempo de experiência na enfermagem.

O sexo feminino representou o percentual de $87 \%$ dos participantes, $56 \%$ para o grupo do Complemento e $31 \%$ para o da Especialização. Para homens e mulheres $(n=150)$, a faixa etária de 31 a quarenta anos foi a mais frequente, totalizando, respectivamente, 68 e vinte enfermeiras(os). Entretanto, especificamente para os participantes do Curso de Especialização $(n=51)$, a faixa etária de vinte a trinta anos foi a mais frequente para a maioria (54,9\%).

Quanto ao tempo de trabalho na Área da Enfermagem, o período entre 11 e vinte anos foi mais frequente para os que cursaram o Complemento. A maioria dos integrantes do grupo da Especialização em Materno tinha, no máximo, dez anos de experiência na área.

A caracterização dos participantes da pesquisa teve como objetivo fazer breve contextualização, sem o intuito de visualizar o conjunto de conhecimentos do grupo, mas com interesse de destacar as diferenciações, como, por exemplo, a pouca idade e tempo de experiência profissional. Entretanto, entende-se que a representação da violência contra a mulher independe dos referidos fatores, mas do solo cultural onde os sujeitos de pesquisa estão inseridos. Portanto, neste estudo, não foram feitas comparações entre as variáveis.

A seguir, apresentam-se os resultados relacionados às Representações Sociais da violência contra a mulher sob a ótica das enfermeiras em estudo. Salienta-se que, para referir-se aos participantes da pesquisa, optou-se por usar o termo enfermeira, no feminino, por ser um contingente majoritário.

As respostas dos cento e cinquenta participantes, referentes aos cinco estímulos, totalizaram 4.058 palavras, com 967 (28,3\%) palavras distintas. Para a análise de cada um dos estímulos, consideraramse as palavras retidas com frequência superior a nove.

Das respostas ao $1^{\circ}$ estímulo, "Quando penso em violência, lembro-me de...", resultaram 852 palavras, com $236(27,7 \%)$ palavras distintas. Com a frequência superior a nove, resultaram 425 palavras, das quais 17 distintas, que são apresentadas no Quadro 1.

Quadro 1. Palavras retidas por ordem de frequência superior a nove, relacionadas ao estímulo "Quando penso em violência, lembro-me de...". $n=150$

\begin{tabular}{|l|l|}
\hline \multicolumn{1}{|c|}{ Palavras retidas } & Frequência \\
\hline agressão & 58 \\
\hline dor & 57 \\
\hline agressão física & 42 \\
\hline agressão psicológica & 35 \\
\hline maus-tratos & 35 \\
\hline lesões & 24 \\
\hline sofrimento & 23 \\
\hline medo & 23 \\
\hline guerra & 22 \\
\hline
\end{tabular}

\begin{tabular}{|l|c|}
\hline \multicolumn{1}{|c|}{ Palavras retidas } & Frequência \\
\hline choro & 20 \\
\hline angústia & 13 \\
\hline mulheres & 13 \\
\hline violação & 13 \\
\hline tristeza & 12 \\
\hline gritos & 12 \\
\hline crianças & 11 \\
\hline sangue & 11 \\
\hline
\end{tabular}

Fonte: SMCL, Lisboa, 2008. 
As seis palavras mencionadas com maior frequência foram: agressão, dor, agressão física, agressão psicológica, maus-tratos e lesões, que indicam agressão física e psicológica, associada com lesões físicas.

A palavra agressão apareceu 58 vezes e a palavra sangue, 11 vezes, frequências máxima e mínima estabelecidas, o que representa que, nesse primeiro momento, a agressão física foi mais evidente.

No Quadro 2, apresenta-se a Análise Fatorial de Correspondência Simples relacionada ao estímulo "Quando penso em violência, lembro-me de...".

Quadro 2. AFC Simples relacionada ao estímulo "Quando penso em violência, lembro-me de...". n = 150

\begin{tabular}{|c|l|l|}
\hline Fatores & \multicolumn{1}{|c|}{ Coordenadas (+) Contribuições absolutas } & \multicolumn{1}{|c|}{ Coordenadas (-) Contribuições absolutas } \\
\hline $\begin{array}{c}\text { F1 } \\
\text { agressão física }\end{array}$ & agressão física (27.3) agressão psicológica (23.8) & $\begin{array}{l}\text { tristeza (14.2) } \\
\text { dor (9.9) }\end{array}$ \\
\hline $\begin{array}{c}\text { F2 } \\
\text { mulheres }\end{array}$ & $\begin{array}{l}\text { maus-tratos (11.3) } \\
\text { violação (6.3) }\end{array}$ & $\begin{array}{l}\text { mulheres (27.1) } \\
\text { guerra (12.6) } \\
\text { crianças (10.8) } \\
\text { sangue (9.8) }\end{array}$ \\
\hline $\begin{array}{c}\text { F3 } \\
\text { agressão }\end{array}$ & $\begin{array}{l}\text { agressão física (9.2) } \\
\text { tristeza (20.5) } \\
\text { dor (8.8) }\end{array}$ & $\begin{array}{l}\text { agressão (21.0) } \\
\text { maus-tratos (20.7) } \\
\text { violação (7.7) }\end{array}$ \\
\hline
\end{tabular}

Fonte: SMCL, Lisboa, 2008.

No Quadro 2, para o $1^{\circ}$ estímulo, "Quando penso em violência, lembro-me de...", os fatores isolados foram: agressão física (F1), mulheres (F2) e maus-tratos (F3).

Em relação a $F 1$, pode-se considerar que a violência é representada pela agressão física (27.3) e outros tipos de agressão, causando tristeza e dor às pessoas, em geral, uma vez que a violência contra a mulher não é citada.

Entretanto, F2 é explicado pela palavra mulheres (27.1), à qual se associa guerra, maus-tratos e criança. Guerra é o espaço onde ocorrem as maiores atrocidades, violência, maus-tratos, e as principais vítimas são as mulheres e as crianças.

No terceiro fator, a palavra agressão (21.0) seguida de maus-tratos e tristeza, pode significar que, além das lesões físicas, as marcas da violência podem ser expressas por sinais de maus-tratos, tristeza, dor e violação.

A palavra Agressão psicológica $(28,3)$ domina o polo positivo e Mulheres (27.1) o polo negativo; portanto, a agressão psicológica contra a mulher pode ser, aqui, entendida como referência nos casos de mulheres em situação de violência.

No $2^{\circ}$ estímulo, "Quando penso em violência contra a mulher, lembro-me de...", identificaram-se 858 palavras, das quais, 274 distintas (31,9\%). Ao considerar a frequência de palavras superior a 9 , resultaram 414 palavras, com 25 distintas, apresentadas no Quadro 3. 
Quadro 3. Palavras retidas por ordem de frequência superior a nove, relacionadas ao estímulo "Quando penso em violência contra a mulher, lembro-me de...". $n=150$

\begin{tabular}{|l|c|}
\hline \multicolumn{1}{|c|}{ Palavras retidas } & Frequência \\
\hline dor & 32 \\
\hline agressão física & 30 \\
\hline agressão psicológica & 24 \\
\hline violação & 24 \\
\hline sofrimento & 24 \\
\hline agressão & 21 \\
\hline medo & 20 \\
\hline maus-tratos & 17 \\
\hline mulheres & 17 \\
\hline discriminação & 16 \\
\hline revolta & 15 \\
\hline covardia & 15 \\
\hline lesões & 15 \\
\hline
\end{tabular}

\begin{tabular}{|l|c|}
\hline \multicolumn{1}{|c|}{ Palavras retidas } & Frequência \\
\hline homem & 15 \\
\hline silêncio & 13 \\
\hline humilhação & 13 \\
\hline crime & 13 \\
\hline injustiça & 12 \\
\hline tristeza & 12 \\
\hline solidão & 12 \\
\hline vergonha & 12 \\
\hline fragilidade & 12 \\
\hline choro & 11 \\
\hline angústia & 10 \\
\hline abuso & 10 \\
\hline
\end{tabular}

Fonte: SMCL, Lisboa, 2008.

As palavras mais frequentes são: dor, agressão física, agressão psicológica, violação, sofrimento e agressão. Dor é citada 32 vezes, e as palavras angústia e abuso dez vezes, frequências máxima (32) e mínima (dez) estabelecidas, o que aponta para a representação da violência contra a mulher relacionada à dor (física e/ou psíquica) e ao abuso. O sentimento de angústia pode estar relacionado à situação da mulher, mas, também, às dificuldades das enfermeiras para lidarem com a questão.

No Quadro 4, apresenta-se a Análise Fatorial de Correspondência Simples relacionada ao estímulo "Quando penso em violência contra a mulher, lembro-me de...".

Quadro 4. AFC Simples relacionada ao estímulo "Quando penso em violência contra a mulher lembro-me de..." $\mathrm{n}=150$

\begin{tabular}{|c|l|l|}
\hline Fatores & \multicolumn{1}{|c|}{ Coordenadas (+) Contribuições absolutas } & \multicolumn{1}{|c|}{ Coordenadas (-) Contribuições absolutas } \\
\hline $\begin{array}{c}\text { F1 } \\
\text { covardia }\end{array}$ & $\begin{array}{l}\text { agressão psicológica (12.0) } \\
\text { agressão física (11.0) } \\
\text { agressão (6.7) } \\
\text { violação (5.6) }\end{array}$ & $\begin{array}{l}\text { covardia (34.8) } \\
\text { humilhação (7.3) }\end{array}$ \\
\hline $\begin{array}{c}\text { F2 } \\
\text { covardia }\end{array}$ & $\begin{array}{l}\text { covardia (33.7) } \\
\text { lesões (6.3) } \\
\text { agressão psicológica (6.7) }\end{array}$ & $\begin{array}{l}\text { tristeza (21.9) } \\
\text { abuso (6.4) }\end{array}$ \\
\hline $\begin{array}{l}\text { F3 } \\
\text { lesões }\end{array}$ & $\begin{array}{l}\text { lesões (19.3) } \\
\text { fragilidade (8.9) }\end{array}$ & $\begin{array}{l}\text { covardia (15.4) } \\
\text { agressão (14.0) } \\
\text { maus-tratos (10.2) } \\
\text { abuso (9.2) }\end{array}$ \\
\hline
\end{tabular}

Fonte: SMCL, Lisboa, 2008. 
Na extração dos universos semânticos das palavras relacionadas ao estímulo "Quando penso em violência contra a mulher, lembro-me de...", covardia representou majoritariamente os dois primeiros fatores: F1 (34.8), F2 (33.7). Também dominou os polos positivos e negativos, o que reforça o significado da palavra no contexto da violência contra a mulher. O F3 foi representado pelas lesões decorrentes da violência, associadas a covardia, agressão e maus-tratos.

No F1, covardia está associada, sobretudo, às palavras agressão psicológica e agressão física, o que vai ao encontro de resultados de pesquisas que indicam que as mulheres em situação de violência estão expostas à agressão psicológica e a ameaças do agressor (ex-marido, ex-companheiro), o que, na maioria das vezes, as impede de denunciarem as agressões sofridas (Soares, 2005).

Em F2, a palavra covardia está associada, sobretudo, à tristeza. No F3, a palavra lesões associa-se a covardia, agressão e maus-tratos, o que ressalta o comprometimento psicológico e as lesões físicas resultantes da agressão. A tristeza pode ser representada tanto pelo sentimento da mulher, quanto por tudo que a envolve e sua família. Também pode-se considerar que a covardia e o sentimento de posse são as principais características do agressor, e que, na maioria das vezes, o motivo da agressão é o ciúme (Deeke et al., 2009; Barroso, 2007). Destaca-se que o ciúme e o sentimento de posse foram os principais motivos apontados por mulheres portuguesas agredidas por (ex-)companheiro íntimo (Lisboa, 2009, 2008).

Em relação à agressão psicológica, Paim (2006, p.10) ressalta que "antes do agressor poder ferir fisicamente sua companheira, precisa baixar sua auto-estima de tal forma que ela tolere as agressões"; explica que, frequentemente, ele começa buscando diminuir a mulher, mediante pequenas coisas que ela diz ou faz, até sentir-se tão insignificante e considerar necessitar da ajuda dele até para decidir pequenas situações do dia a dia. Este movimento da violência é sutil, muitas vezes, imperceptível para ambos; com muita frequência, a mulher tende a justificar e entender o padrão de comportamento do agressor (Silva, Coelho, Caponi, 2007).

Para o $3^{\circ}$ estímulo, "Quando penso em cuidar de uma mulher que procurou o serviço de saúde por ter sido agredida pelo (ex-)marido, (ex-)companheiro, (ex-)namorado, lembro-me de...", foram citadas 923 palavras, das quais $311(33,7 \%)$ são diferentes. Considerando-se a frequência maior que nove, apareceram 379, com 17 palavras distintas, descritas no Quadro 5.

Quadro 5. Palavras retidas por ordem de frequência superior a nove, relacionadas ao estímulo "Quando penso em cuidar de uma mulher que procurou o serviço de saúde por ter sido agredida pelo (ex-)marido, (ex-)companheiro, (ex-)namorado, lembro-me de...". $\mathrm{n}=150$

\begin{tabular}{|l|c|}
\hline \multicolumn{1}{|c|}{ Palavras retidas } & Frequência \\
\hline apoio & 69 \\
\hline ajuda & 51 \\
\hline encaminhar & 33 \\
\hline cuidar & 23 \\
\hline compreensão & 21 \\
\hline denúncia & 20 \\
\hline mulheres & 19 \\
\hline ouvir & 19 \\
\hline revolta & 18 \\
\hline
\end{tabular}

\begin{tabular}{|l|c|}
\hline \multicolumn{1}{|c|}{ Palavras retidas } & Frequência \\
\hline proteção & 17 \\
\hline empatia & 16 \\
\hline escutar & 15 \\
\hline carinho & 14 \\
\hline confortar & 12 \\
\hline compaixão & 11 \\
\hline polícia & 10 \\
\hline medo & 10 \\
\hline
\end{tabular}

Fonte: SMCL, Lisboa, 2008. 
As palavras mais frequentes foram: apoio, ajuda, encaminhar, cuidar, compreensão e denúncia, que demonstram o sentimento relacionado ao apoio e cuidado às mulheres em situação de violência, associados à indicação de denúncia. A palavra apoio aparece 69 vezes, e as palavras polícia e medo, dez vezes cada uma, com frequência máxima e mínima estabelecida, o que reforça a representação de apoio às mulheres; entretanto as palavras medo e polícia também podem indicar as dificuldades enfrentadas quando a mulher é encaminhada para a denúncia. Além da sua exposição aos policiais, o medo também representa as ameaças do agressor e o risco de ser agredida mais severamente por ter feito a queixa policial.

A seguir, no Quadro 6, apresenta-se a Análise Fatorial de Correspondência Simples relacionada ao estímulo "Quando penso em cuidar de uma mulher que procurou o serviço de saúde por ter sido agredida pelo (ex-)marido, (ex-) companheiro, (ex-)namorado, lembro-me de...".

Quadro 6. AFC Simples relacionada ao estímulo "Quando penso em cuidar de uma mulher que procurou o serviço de saúde por ter sido agredida pelo (ex-)marido/ (ex-)companheiro/ (ex-)namorado, lembro-me de...". $n=150$

\begin{tabular}{|c|c|c|}
\hline Fatores & Coordenadas $(+)$ Contribuições absolutas & Coordenadas (-) Contribuições absolutas \\
\hline $\begin{array}{l}\text { F1 } \\
\text { revolta }\end{array}$ & $\begin{array}{l}\text { revolta (54.4) } \\
\text { compaixão (29.9) }\end{array}$ & apoio (3.7) \\
\hline $\begin{array}{c}\text { F2 } \\
\text { confortar }\end{array}$ & confortar (74.5) & $\begin{array}{l}\text { carinho (5.5) } \\
\text { polícia (3.6) }\end{array}$ \\
\hline $\begin{array}{l}\text { F3 } \\
\text { carinho }\end{array}$ & $\begin{array}{l}\text { carinho (33.3) } \\
\text { compreensão (4.1) }\end{array}$ & $\begin{array}{l}\text { polícia (24.8) } \\
\text { medo (12.1) } \\
\text { revolta }(9.7) \\
\text { denúncia }(6.7)\end{array}$ \\
\hline
\end{tabular}

Fonte: SMCL, Lisboa, 2008.

No Quadro 6, para o estímulo "Quando penso em cuidar de uma mulher que procurou o serviço de saúde por ter sido agredida pelo (ex-)marido, (ex-) companheiro, (ex-)namorado, lembro-me de...", os fatores isolados foram: revolta (F1), confortar (F2) e carinho (F3). O primeiro fator (F1) pode ser denominado fator de revolta (54.4), palavra que praticamente explica este polo e está associada ao sentimento de compaixão. O segundo fator (F2) é explicado pela palavra confortar (74.5), e o terceiro (F3), pela palavra carinho (33.3) acompanhada de polícia, o que representa que a enfermeira, primeiro, procura confortar a mulher em situação de violência, para, depois, encaminhá-la à polícia, ou seja, instrumentalizar a mulher para fazer a denúncia da agressão.

A palavra confortar (74.5) domina o polo positivo e pode ser considerada como referência para a ação das enfermeiras frente à mulher em situação de violência, sendo que a palavra polícia (24.8) domina o polo negativo e está relacionada, sobretudo, ao medo, reforçando, mais uma vez, a exposição da mulher aos policiais e às dificuldades enfrentadas no encaminhamento da denúncia da violência contra a mulher.

Considera-se importante confortar a mulher em situação de violência e agir com ações de carinho; essas, entretanto, são atitudes restritas à esfera de cunho pessoal. Para o enfrentamento do problema, utilizam-se ações técnicas, como o esclarecimento sobre seus direitos de mulher, sendo que a articulação dos serviços com centros de referência no atendimento e com ONGs de apoio auxiliam a mulher no enfrentamento do problema.

Resultados da pesquisa realizada em Portugal, sobre a representação social de profissionais de saúde acerca da violência contra a mulher, identificaram que $60 \%$ das enfermeiras entrevistadas consideravam que as mulheres ficavam perturbadas se fossem questionadas sobre a violência doméstica, e $28 \%$ tinham 
receio de ofender a paciente se questionassem sobre o assunto (Gonçalves, 2004), o que pode justificar o atendimento restrito ao conforto e carinho. Nessa perspectiva, entende-se que ainda não está estabelecida, entre os profissionais de saúde, a inclusão da violência como causa na demanda dos serviços.

As representações culturais são decisivas para o desenvolvimento das identidades da sociedade contemporânea e possuem um papel determinante na construção das identidades de gênero, como um poderoso instrumento para a "manutenção da discriminação e subalternidade das mulheres" (Aguado 2005, p.23). Nessa perspectiva, a violência contra a mulher é considerada uma questão privada, e não um problema de Saúde Pública.

O $4^{\circ}$ estímulo, "Quando penso na contribuição da minha formação acadêmica e profissional, para identificar uma mulher vítima de violência, lembro-me de...", desencadeou a citação de 716 palavras, das quais $305(42,6 \%)$ são distintas. As palavras retidas, com frequência superior a nove, totalizaram 217, com 14 distintas, que estão listadas no Quadro 7.

Quadro 7. Palavras retidas por ordem de frequência superior a nove, relacionadas ao estímulo "Quando penso na contribuição da minha formação acadêmica e profissional, para identificar uma mulher vítima de violência, lembro-me de...". $n=150$

\begin{tabular}{|l|c|}
\hline \multicolumn{1}{|c|}{ Palavras retidas } & Frequência \\
\hline apoio & 29 \\
\hline sinais & 25 \\
\hline observar & 18 \\
\hline cuidar & 17 \\
\hline empatia & 17 \\
\hline ajuda & 17 \\
\hline encaminhar & 16 \\
\hline
\end{tabular}

\begin{tabular}{|l|c|}
\hline \multicolumn{1}{|c|}{ Palavras retidas } & Frequência \\
\hline mulheres & 15 \\
\hline escutar & 11 \\
\hline vítima & 11 \\
\hline ouvir & 11 \\
\hline violência & 10 \\
\hline relação de ajuda & 10 \\
\hline saber & 10 \\
\hline
\end{tabular}

Fonte: SMCL, Lisboa, 2008.

As palavras mais frequentes foram: apoio, sinais, observar, cuidar, empatia e ajuda, todas relacionadas ao apoio e ao cuidado. A palavra apoio foi citada 29 vezes e as palavras violência, relação de ajuda e saber, dez vezes cada uma, com frequência máxima e mínima estabelecida. Podese considerar que o apoio e a relação de ajuda às mulheres em situação de violência exigem que a enfermeira tenha respaldo teórico sobre o tema para saber agir e identificar os casos.

No Quadro 8, apresenta-se a Análise Fatorial de Correspondência Simples relacionada ao estímulo "Quando penso na contribuição da minha formação acadêmica e profissional, para identificar uma mulher vítima de violência, lembro-me de...", $n=150$.

Na extração dos universos semânticos das palavras relacionadas ao estímulo "Quando penso na contribuição da minha formação acadêmica e profissional, para identificar uma mulher vítima de violência, lembro-me de...", os fatores isolados foram: sinais (F1), vítima (F2) e apoio (F3). 
Quadro 8. AFC Simples relacionada ao estímulo "Quando penso na contribuição da minha formação acadêmica e profissional, para identificar uma mulher vítima de violência, lembro-me de...". n = 150

\begin{tabular}{|c|l|l|}
\hline Fatores & \multicolumn{1}{|c|}{ Coordenadas (+) Contribuições absolutas } & \multicolumn{1}{c|}{ Coordenadas (-) Contribuições absolutas } \\
\hline $\begin{array}{c}\text { F1 } \\
\text { sinais }\end{array}$ & $\begin{array}{l}\text { apoio (7.9) } \\
\text { cuidar (3.6) }\end{array}$ & $\begin{array}{l}\text { sinais (38.9) } \\
\text { violência (20.5) } \\
\text { mulheres (15.9) }\end{array}$ \\
\hline $\begin{array}{c}\text { F2 } \\
\text { vítima }\end{array}$ & $\begin{array}{l}\text { mulheres (6.6) } \\
\text { relação de ajuda (6.3) }\end{array}$ & vítima (65.0) \\
\hline $\begin{array}{c}\text { F3 } \\
\text { apoio }\end{array}$ & $\begin{array}{l}\text { apoio (22.1) } \\
\text { violência (13.0) } \\
\text { ajuda (8.1) }\end{array}$ & $\begin{array}{l}\text { saber (12.5) } \\
\text { mulheres (10.9) } \\
\text { observar (11.5) }\end{array}$ \\
\hline
\end{tabular}

Fonte: SMCL, Lisboa, 2008.

No primeiro fator (F1), a palavra sinais (38.9), associada a violência e mulheres, pode indicar que, na sua formação profissional, as enfermeiras foram informadas sobre a identificação dos casos, ou, ainda, que não tiveram acesso ao conhecimento dos sinais da violência contra a mulher e estão buscando as informações.

O F2 é representado pela palavra vítima (65.0) relacionada à palavra mulher, o que ajuda a identificá-la como vítima; entretanto, este entendimento dificulta as ações voltadas ao seu empoderamento, uma vez que, ao ser considerada "vítima", é excluída sua participação na relação, a possibilidade de ser sujeito da ação e de romper o ciclo da violência. Considera-se que o fato de a palavra vítima estar inserida na questão estímulo pode ter influenciado na representação, porém, ressalta-se que, em nenhum momento, houve o questionamento do termo, indicando a naturalização da mulher como vítima.

Nessa perspectiva, na Área da Saúde, considerar a pessoa como vitima é "significá-la como detentora de menor potencialidade diante das suas possibilidades de vir a ser sujeito plenamente potente, de deter auto-domínio e soberania de decisões" (Schraiber, D'Oliveira, 1999, p.15). Portanto, ao considerar a mulher vítima, se "perpetua a noção da mulher como um sujeito incapaz, à semelhança das crianças, dos doentes ou dos loucos, em maior grau! Incapaz de decisões, incapaz de pleno domínio de si... então necessitaria de eternos tutores" (Schraiber, D'Oliveira, 1999, p.5).

No terceiro fator (F3), a palavra apoio, associada às palavras violência, saber e mulheres, reforça a ideia de que é necessário respaldo teórico para identificar as mulheres em situação de violência, para saber quais as ações de enfermagem e "o que fazer" frente à violência como demanda, nos atendimentos de saúde.

Entretanto, a representação das enfermeiras fica restrita à esfera "do apoio" e não se vincula ao comprometimento institucional de identificar os sintomas, reconhecer a mulher em situação de violência e incluir os demais encaminhamentos que envolvem o atendimento de saúde às mulheres em situação de violência. Resultado de pesquisa realizada em um hospital de trauma, no Brasil, identificou que os profissionais da enfermagem lidam com seus conflitos individual e coletivamente, e que não há uma preocupação do hospital em dar um suporte psicológico para que eles possam enfrentar as dificuldades do dia a dia (Leal, 2003).

Borsoi, Brandão, Cavalcanti (2009, p.167) ressaltam "que os serviços de saúde têm o dever de se constituir como um local de acolhimento e elaboração de projetos de apoio" às mulheres em situação de violência. Concorda-se com as autoras citadas e considera-se que, além da formação acadêmica, voltada ao reconhecimento e identificação dos atendimentos das mulheres em situação de violência, o envolvimento e o respaldo institucional possibilitam a construção de ações voltadas ao atendimento integral. 
O $5^{\circ}$ e último estímulo, "Quando penso se a violência contra a mulher é um problema de Saúde Pública ou um caso de polícia, lembro-me de...", totalizou 709 palavras, com $327(46,1 \%)$ distintas, sendo que aquelas com frequência superior a nove constituíram 213, das quais as 13 diferentes são citadas no Quadro 9.

Quadro 9. Palavras retidas por ordem de frequência superior a nove, relacionadas ao estímulo "Quando penso se a violência contra a mulher é um problema de saúde pública ou um caso de polícia, lembro-me de...". n = 150

\begin{tabular}{|l|c|}
\hline \multicolumn{1}{|c|}{ Palavras retidas } & Frequência \\
\hline apoio & 41 \\
\hline leis & 22 \\
\hline vítima & 19 \\
\hline mulheres & 17 \\
\hline família & 16 \\
\hline polícia & 16 \\
\hline denúncia & 15 \\
\hline
\end{tabular}

\begin{tabular}{|l|c|}
\hline \multicolumn{1}{|c|}{ Palavras retidas } & Frequência \\
\hline comunidade & 13 \\
\hline sociedade & 12 \\
\hline proteção & 11 \\
\hline educação & 11 \\
\hline social & 10 \\
\hline ajuda & 10 \\
\hline
\end{tabular}

Fonte: SMCL, Lisboa, 2008.

As palavras retidas com maior frequência foram: apoio, leis, vítima, mulheres, família, polícia explicitando que a representação da violência contra a mulher ainda está mais inserida no campo policial do que na Área da Saúde, portanto não é considerada um "problema de Saúde Pública".

A palavra apoio foi citada 41 vezes e as palavras social e ajuda, dez vezes cada uma, com frequência máxima e mínima estabelecida, o que pode indicar que o apoio à mulher em situação de violência está ancorado à ajuda social na figura da assistente social e de organizações não governamentais, reforçando mais a exclusão do tema na Área da Saúde.

No Quadro 10, apresenta-se a Análise Fatorial de Correspondência Simples relacionada ao estímulo "Quando penso se a violência contra a mulher é um problema de Saúde Pública ou um caso de polícia, lembro-me de...".

Quadro 10. AFC Simples relacionada ao estímulo "Quando penso se a violência contra a mulher é um problema de Saúde Pública ou um caso de polícia, lembro-me de...". $n=150$

\begin{tabular}{|c|l|l|}
\hline Fatores & \multicolumn{1}{|c|}{ Coordenadas (+) Contribuições absolutas } & \multicolumn{1}{c|}{ Coordenadas (-) Contribuições absolutas } \\
\hline $\begin{array}{c}\text { F1 } \\
\text { social }\end{array}$ & $\begin{array}{l}\text { família (18.9) } \\
\text { social (40.0) }\end{array}$ & educação (25.4) \\
\hline $\begin{array}{c}\text { F2 } \\
\text { educação }\end{array}$ & $\begin{array}{l}\text { educação (27.5) } \\
\text { sociedade (12.5) }\end{array}$ & $\begin{array}{l}\text { ajuda (18.1) } \\
\text { vítima (6.1) }\end{array}$ \\
\hline F3 & $\begin{array}{l}\text { leis (16.4) } \\
\text { polícia (7.4) }\end{array}$ & $\begin{array}{l}\text { ajuda (47.6) } \\
\text { social (8.0) } \\
\text { educação (7.1) }\end{array}$ \\
\hline
\end{tabular}

Fonte: SMCL, Lisboa, 2008. 
Os fatores isolados relacionados a esse $5^{\circ}$ estímulo foram: social (F1), educação (F2) e ajuda (F3).

O primeiro fator (F1), denominado social (40.0), está associado às palavras educação e família.

Nessa perspectiva, pode-se considerar que a representação da violência contra a mulher está voltada ao papel da educação e da família.

No segundo fator (F2), a educação (27.5) aparece novamente em destaque, relacionada às palavras ajuda e sociedade. No terceiro fator (F3), a palavra ajuda (47.6) está associada à palavra leis. Portanto, para as enfermeiras que participaram desta pesquisa, a violência contra a mulher não é considerada um caso de polícia; pode ser um problema público (social), mas ainda não é entendida como um problema de Saúde Pública.

Os resultados deste estudo vão ao encontro do que Borsoi, Brandão e Cavalcanti (2009, p.170) identificaram ao entrevistarem profissionais de saúde de serviços de atenção básica, no Rio de Janeiro, sobre questões que envolvem a violência contra a mulher. As autoras afirmam que "apesar de conseguirem identificá-la, alguns profissionais ainda encontram dificuldade em perceber a violência como demanda de ação específica para o setor saúde".

Resultados de estudo português, realizado com mulheres atendidas em Centros de Saúde do país, revelaram que cerca da metade das vítimas estabelece relação de causalidade entre a violência e os efeitos negativos relacionados à família e aos amigos, na qual os membros da família se destacam $(40,2 \%)$, sendo, na sua maioria, filhos $(58,8 \%)$. Assim, concorda-se com os autores citados que, depois das próprias mulheres, os filhos, em especial as crianças, são as maiores vítimas dos atos de violência (Lisboa, Barros, Cerejo, 2008).

Ainda referindo-se ao mesmo estudo, cerca de um quinto das mulheres inquiridas tiveram filhos doentes, nos 12 meses anteriores à realização da pesquisa (21,2\%); os autores ressaltam que a probabilidade de isso acontecer com as que estão em situação de violência é $50 \%$ maior do que com as não-vítimas (Lisboa, Barros, Cerejo, 2008).

Portanto, considera-se que a identificação e o acolhimento das mulheres em situação de violência nos atendimentos dos serviços de saúde é o início da sensibilização para a visibilização da questão como um problema de Saúde Pública que abrange tanto a saúde da mulher, quanto a da sua família, em especial a dos seus filhos (Lisboa, 2006, 2009).

O Relatório Mundial de Saúde destaca que são inúmeras as consequências da violência perpetrada por (ex-)parceiro íntimo, na saúde das mulheres e dos seus filhos, e, ainda, que elas buscam, com muita frequencia, os serviços de saúde; a maioria espera que os profissionais de saúde inquiram sobre a violência, não com a expectativa de que resolvam o seu problema, mas de serem escutadas, tratadas e ajudadas a assumirem o controle das suas decisões. Porém, na maioria das vezes, esses profissionais têm dificuldade em interrogá-las sobre a violência, sobretudo, por falta de formação e competência. Entretanto, estão em posição privilegiada para identificar essas usuárias, incluindo a sua referenciação para apoios psicossociais, legais, entre outros. A "intervenção permite reduzir o impacto da violência na saúde e no bem-estar da mulher, bem como das suas crianças, e pode igualmente ajudar a impedir futuros episódios de violência" (OMS, 2008, p.49).

\section{Considerações finais}

A violência foi representada pelas enfermeiras como agressão física associada à tristeza e à dor, que podem ser decorrentes dos ferimentos e do sofrimento da mulher por ser agredida por alguém que é ou foi tão próximo/intimo, com quem tem ou teve laços afetivos recentes. A associação com guerra, maus-tratos e crianças pode estar relacionada à guerra em si, mas, também, à situação "guerra" vivida por uma família, na qual a mulher é agredida pelo marido/companheiro, o que, na maioria dos casos, resulta em maus-tratos às crianças. Por último, a agressão associada a maus-tratos e tristeza pode representar as marcas da violência expressas por tristeza, dor e violação.

Na perspectiva das enfermeiras, a violência contra a mulher foi representada, majoritariamente, como uma ação de covardia associada à agressão psicológica, agressão física, tristeza e maus-tratos. 
Entretanto, a representação da violência contra a mulher, no âmbito da ação das enfermeiras frente a essa situação, ficou restrita ao universo consensual (senso cumum), no qual a revolta, o conforto e o carinho representaram o que pesam quando cuidam de uma mulher que procurou o serviço de saúde por ter sido agredida pelo (ex-)marido, (ex-)companheiro, (ex-)namorado. Considera-se que a construção do universo reificado é resultante tanto do embasamento teórico sobre o tema, como do envolvimento institucional e inserção da violência contra a mulher na agenda dos serviços de saúde.

Nessa perspectiva, a contribuição da formação acadêmica e profissional, para identificar uma mulher em situação de violência, foi expressa pela extração dos universos semânticos, cujos fatores isolados foram as palavras: sinais, vítima e apoio. Ressalta-se que o apoio pode auxiliar a mulher a enfrentar a situação. Porém a ajuda, em muitos casos, só é possível quando ela já está em condições de ser ajudada, ou seja, conseguiu identificar que está em situação de violência e decidiu romper com esse ciclo. Ressalta-se que, para chegarem a este estágio, na maioria dos casos, as mulheres ficam submetidas ao domínio do agressor por mais de uma década.

Quanto à questão se violência contra a mulher é um problema de Saúde Pública ou um caso de polícia, a representação da violência contra a mulher está voltada ao papel da educação, da família e da sociedade, no âmbito da ajuda e das leis. As enfermeiras que participaram da pesquisa não consideraram a violência contra a mulher um caso de polícia, nem um problema de Saúde Pública; para elas, é um problema social, que envolve educação, família, leis e ajuda social.

Entende-se que a violência contra a mulher é um problema de Saúde Pública, entretanto, na maioria dos países, assim como no Brasil e em Portugal, nas Instituições de saúde, ainda estão sendo necessários investimentos referentes à criação de uma cultura institucional voltada à identificação das mulheres em situação de violência, bem como ações nas quais os profissionais de saúde estejam instrumentalizados e respaldados para enfrentar as situações. Dessa forma, a violência contra a mulher pode ser incluída em uma agenda de "atenção" para além dos atendimentos, considerada um problema de saúde, com responsabilização e comprometimento institucional dos serviços no campo intersetorial, com a implementação efetiva da referência e contrarreferência, além de constante suporte, teórico e psicológico, aos profissionais de saúde envolvidos nesses atendimentos.

\section{Colaboradores}

As autoras Sandra Maria Cezar Leal, Marta Julia Marques Lopes e Maria Filomena Mendes Gaspar participaram, igualmente, de todas as etapas de elaboração do manuscrito.

\section{Referências}

AGUADO, A. Violencia de género sujeto femenino y ciudadanía en la sociedad contemporánea. In: CASTILLO-MARTíN, M.; OLIVEIRA, S. (Orgs.). Marcadas a ferro. Brasília: Secretaria Especial de Políticas para as Mulheres, 2005. p.23-34.

AMÂNCIO, L.; CARAPINHEIRO, G. Dimensões do poder e do saber: uma abordagem exploratória. In: GONÇALVES, M.E. (Org.). Comunidade científica e poder. Lisboa: Edições 70, FPASC, 1993. p.55-71.

ARRUDA, A. Teoria das representações sociais e teorias de gênero. Cad. Pesqui., n.117, p.127-47, 2002.

BARROSO, Z. Violência nas relações amorosas: uma análise sociológica dos casos detectados nos Institutos de Medina Legal de Coimbra e do Porto. Lisboa: Edições Colibri/ SociNova, 2007. 
BORSOI, T.S.; BRANDÃO, E.R.; CAVALCANTI, M.L.T. Ações para o enfrentamento da violência contra a mulher em duas unidades de atenção primária à saúde no município do Rio de Janeiro. Interface - Comunic., Saude, Educ., v.13, n.28, p.165-74, 2009.

BRASIL. Ministério da Saúde. Conselho Nacional de saúde. Resolução 196/96 sobre pesquisa envolvendo seres humanos. Diário Oficial da União, 10 out. 1996, p.21082-5.

CARMO, I. Custos com a saúde física. In: LISBOA, M. (Org.). Prevenir ou remediar: os custos sociais e econômicos da violência contra as mulheres. Lisboa: Edições Colibri/ SociNova, 2006. p.77-94.

DEEKE, L.P. et al. A dinâmica da violência doméstica: uma análise a partir dos discursos da mulher agredida e de seu parceiro. Saude Soc., v.18, n.2, p.248-58, 2009.

GASPAR, M. F. et al. Percepção e imagens do papel do enfermeiro chefe. Pensar Enferm., V.4, n.2, p.4-11, 2000.

GONÇALVES, A.S.A.T. A violência doméstica contra as mulheres enquanto problema de saúde pública: as representações sociais dos profissionais de saúde portugueses face a esta questão. 2004. Dissertação (Mestrado) - Faculdade de Medicina, Coimbra, 2004.

LEAL, S.M.C. Violência como objeto da assistência em um hospital de trauma: o "olhar" da enfermagem. 2003. Dissertação (Mestrado) - Escola de Enfermagem, Universidade Federal do Rio Grande do Sul, Porto Alegre. 2003.

LEAL, S.M.C.; LOPES, M.J.M. Violência como objeto da assistência em um hospital de trauma: o "olhar" da enfermagem. Cienc. Saude Colet., v.10, n.2, p.419-31, 2005.

LEBART, L. DtmVic 4.3. Paris: Telecom-Paristech, 2008. Disponível em: <http://ses. telecom-paristech.fr/lebart/>. Acesso em: 14 dez. 2008.

LISBOA, M. (Org.). Inquérito violência de género. Região Autónoma dos Açores. Relatório final. Lisboa: Faculdade de Ciências Sociais e Humanas, Universidade Nova de Lisboa, SociNova/CesNova, 2009. v. 1.

(Org.). Inquérito violência de género. Memorando síntese resultados do Inquérito Violência de Género. Faculdade de Ciências Sociais e Humanas, Universidade Nova de Lisboa, SociNova/CesNova, 2008.

Custos sociais: família, amigos, actividade profissional. In: LISBOA, M. (Org.). Prevenir ou remediar: os custos sociais e económicos da violência contra as mulheres. Lisboa: Edições Colibri/SociNova, 2006. p.67-76.

LISBOA, M.; BARROS, P. P.; CEREJO, S.D. Custos sociais e económicos da violência exercida contra as mulheres em Portugal: dinâmicas e processos socioculturais. In: CONGRESSO PORTUGUÊS DE SOCIOLOGIA - MUNDOS SOCIAIS: SABERES E PRÁTICAS, 2008, Lisboa. Anais... Lisboa: Universidade Nova de Lisboa, 2008. p.1-9. Disponível em: <http://www.aps.pt/vicongresso/pdfs/60.pdf>. Acesso em: 30 nov. 2009.

MARINHEIRO, A.L.V.; VIEIRA, E.M.; SOUZA, L. Prevalência da violência contra a mulher usuária de serviço de saúde. Rev. Saude Publica, v.40, n.4, p.604-10, 2006.

MOSCOVICI, S. Representações sociais: investigação em psicologia social. Petrópolis: Vozes, 2003.

A representação social da psicanálise. Rio de Janeiro: Zahar, 1978.

OLIVEIRA, A.; ARAÚJO, G. A magia de Bosch: pertenças sociais e formas de percepção e representação da arte. Anal. Psicol., v.2 , n.17, p.339-57, 1999.

OLIVEIRA, A.; AMARAL, V. A análise factorial de correspondências na investigação em psicologia: uma aplicação ao estudo das representações sociais do suicídio adolescente. Anal. Psicol., v.25, n.2, p.271-93, 2007.

OLIVEIRA, A.; D'OLIVEIRA, A.F.P.L. Violência de gênero contra trabalhadoras de enfermagem em hospital geral de São Paulo (SP). Rev. Saude Publica, v.42, n.5, p.868-76, 2008. 
ORDEM DOS ENFERMEIROS. Decreto-lei n.353/99, de 3 de setembro de 1999. Ensino da Enfermagem: regras gerais do ensino da enfermagem.. 2008. Disponível em: <http://www.ordemenfermeiros.pt/index.php?page=167>. Acesso em: 30 abr. 2009.

ORGANIZAÇÃO MUNDIAL DE SAÚDE. Relatório Mundial de Saúde 2008: cuidados de saúde primários - agora mais do que nunca. Genebra: Organização Mundial da Saúde, 2008. Disponível em: <http://www.who.int/whr/2008/whr08_pr.pdf>. Acesso em: 30 dez. 2009.

PAIM, J. Entendo a violência doméstica. In: PEREIRA, M.A.E. (Org.). Fórum Nacional de Educação em Direitos Humanos. Seminário de Capacitação para juízes, procuradores, promotores, advogados e delegados no Brasil: Protegendo as mulheres da violência doméstica.. Brasília: Secretaria Especial de Políticas para as Mulheres, 2006. p.6-11. Disponível em: <http://midia.pgr.mpf.gov.br/hotsites/diadamulher/docs/cartilha_ violencia_domestica.pdf $>$. Acesso em: 10 jan. 2009.

SÁ, C.P. Representações sociais: o conceito e o estado atual da teoria. In: SPINK, M.J. (Org.). O conhecimento no cotidiano: as representações sociais na perspectiva da psicologia social. São Paulo: Brasiliense, 2004. p.19-45.

SCHRAIBER, L.B.; D'OLIVEIRA, A.F.L.P. Violence against women: interfaces with health care. Interface - Comunic, Saude, Educ., v.3 , n.5, p.11-26, 1999.

SCHRAIBER, L.B. et al. Violência contra a mulher: estudo em uma unidade de atenção primária à saúde. Rev. Saude Publica, v.36, n.4, p.470-7, 2002.

SILVA, L.L.; COELHO, E.B.S.; CAPONI, S.N.C. Violência silenciosa: violência psicológica como condição da violência física doméstica. Interface - Comunic., Saude, Educ., v.11, n.21, p.93-103, 2007.

SOARES, B.M. Enfrentando a violência contra a mulher. Brasília: Secretaria Especial de Políticas para as Mulheres, 2005.

VALA, J. Representações sociais e psicologia social do conhecimento quotidiano. In: VALA, J.; MONTEIRO, M.B. (Orgs.). Psicologia social. 7.ed. Lisboa: Fundação Calouse Gulbenkan, 2006. p.457-502.

LEAL, S.M.C.; LOPES, M.J.M.; GASPAR, M.F.M. Representaciones sociales de la violencia contra la mujer bajo la perspectiva de la enfermería. Interface - Comunic., Saude, Educ., v.15, n.37, p.409-24, abr./jun. 2011.

La violencia contra la mujer es un grave problema de Salud Pública que ocurre mundialmente en todas las clases sociales. El estudio ha investigado las representaciones sociales de la violencia contra la mujer bajo la perspectiva de alumnas de una Escuela Superior de Enfermería de Lisboa, Portugal. De la pesquisa exploratoria participaron 150 enfermeras siendo los datos recolectados por medio de cuestionario. Para analizarlos se utilizó el programa DataVic 4.3. Resultados apuntan que las representaciones sociales de la violencia contra la mujer están restrictas al universo consensual donde se las producen y que se constituyen sobretodo de la conversación informal y de la vida cotidiana. Apuntan, también, que la violencia no se entiende como un problema de salud. Se considera que el basamento teórico acerca del tema y el envolvimiento institucional de los Servicios de Salud contribuirán para la inserción de la violencia contra la mujer en la agenda de Salud Pública.

Palabras clave: Enfermería. Género y Salud. Violencia. Violencia contra la mujer. 